Original Article

\title{
ANALYSIS OF THE ANATOMIC VARIATIONS OF THE BRACHIAL PLEXUS AND ITS BRANCHES AT THE LEVEL OF FORMATION AND BRANCHING OF ITS TRUNCI
}

\author{
Milutin Mrvaljević ${ }^{1}$, Srbislav Pajić ${ }^{1}$, Pavle Popović ${ }^{1}$, Jovan Grujić ${ }^{2}$, Marko Petrović ${ }^{3}$, Ljudmila Jablan ${ }^{4}$, \\ Sonja Giljaca ${ }^{5}$, Petre Stavrevski ${ }^{6}$, Nataša Rančić ${ }^{7}$, Saša Knežević ${ }^{2}$ \\ ${ }^{1}$ Emergency Center KSC, Belgrade, Serbia, \\ ${ }^{2}$ Clinical Center Serbia,Center for Neurosurgery, Belgrade, Serbia \\ ${ }^{3}$ Clinical Center Kragujevac, Center for Neurosurgery, Kragujevac, Serbia \\ ${ }^{4}$ Ostalb-Klinikum Aalen, Baden-Württemberg, Aalen, Germany \\ ${ }^{5}$ Belgrade Public Health Institute Belgrade, Belgrade, Serbia \\ ${ }^{6}$ JZU General Hospital Veles, Veles, Republic of Macedonia \\ ${ }^{7}$ Faculty of MedicineUniversity of Niš, Department of Epidemiology, Niš, Serbia
}

\begin{abstract}
Although the terminal branches of brachial plexus that originate from lateral and medial fasciculus are well protected by muscle mass and vascular-neuronal petal of axilla and upper arm, the number of traumatic damage and injuries increases, according to the published reports of neurosurgeons working on pathology of peripheral nerves, as well as traumatologists, orthopedics, microsurgeons and plastic surgeons. This is certainly contributed by urbanization, industrialization, migration and increased number of traffic accidents. Knowing the microstructure of the peripheral nerve truncus leads to the possibility of applying various techniques of nerve grafting, as well as possibility of re-implantation of detached spinal roots, seen in traction injuries of brachial plexus, in which the mechanism of injury needs to be considered. Considering frequent injuries of terminal branches of lateral and medial fasciculus and a substantial pathology of plexus brachialis, the aim of our research was to study surgical-anatomical relations between terminal branches of medial and lateral fasciculus and substantial morphology of terminal branches of both fasciculi, particularly regarding the place and way of formation, as well as the number of their anastomoses. The studies of the terminal branches of medial and lateral fasciculus on our preparation materials are based on the dissection of axilla and anterior part of the upper arm, on 50 cadavers, adults of both genders, at Institute of Anatomy and Institute of Forensic Medicine at School of Medicine in Belgrade. The way of formation of the terminal branches of lateral fasciculus on our preparation materials was always the same. These branches were usually formed after the bifurcation or diverging of lateral fasciculus to radix lateralis nervi mediani and musculocutaneous nerve. Exceptionally, after fusion of lateral fasciculus and medial root of nervus medianus, there is no bifurcation, and formed nervous truncus is a result of existence of the pre- or postfixational type of brachial plexus. Analyzing our preparation materials, we determined that high bifurcation of lateral fasciculus (LF) exists in $18 \%$ of cases and that it is projected in the line of anterior edge of clavicle. Medium high bifurcation of LF is projected in the line of the top of the acromion of scapula and is seen in $61 \%$ of all cases. Low bifurcation is usually placed in the line of inferior edge of pectoral minor muscle, in $8 \%$ of cases. Fasciculus without bifurcation is noticed in 13\% of cases. Measuring the shortest distance between anterior edge of clavicle and the point of bifurcation of LF resulted in a wide range from 0.5 to $9.7 \mathrm{~cm}$, with $4.2 \mathrm{~cm}$ average. In cases of transplantation, implantation and re-implantation of nervous trunci of plexus brachialis, it is very important to consider the shape and the thickness of nervous truncus, the number of fasciculi, the number of nerve fibers, as well as the quantity and schedule of peri-and intrafascicular connective tissue, providing the normal irrigation of the nerve. Finally, we can conclude that mentioned facts prompted us to undertake a systematic research of great terminal branches of plexus brachialis that originate from lateral and medial fasciculus, trying to ensure that our anatomical findings receive a comprehensive clinical confirmation.
\end{abstract}

Key words: peripheral nerves, brachial plexus, lateral fasciculus, medial fasciculus, truncus.

\section{Introduction}

Correspondence to: Milutin Mrvaljević, M.D.

Emergency Center KSC, Belgrade, 2 Pasterova Str. 11000 Belgrade Serbia

Phone: +38163255187

E-mail: milutin.mrvaljevic@gmail.com

Received February $4^{\text {th }}, 2018$, Accepted June $11^{\text {th }}, 2018$
The first more comprehensive studies of plexus brachialis performed on the autopsy material date back to second half of the past century (Walsch, 1877), and yet the interest of morphologists and clinical researchers still remains current. The great variability of the way of forming the brachial plexus (pre- and postfixation of the 
plexus), its primary trunci, secondary trunci (fasciculi), as well as terminal branches [1-3], contributes to the higher interest for this topic. There is a great variability in view of the place of origin of the plexus, way of forming and its pathway, lateral branches, the great number of mutual anastomoses within the plexus, as well as with adjacent nerves. There is a possibility of potential variations, including those that have not been discovered and described. Therefore, before every surgical treatment, different morphological possibilities of brachial plexus must be considered, due to its great variability and confusing effect on even experienced surgeons [4-6].

During surgical interventions in axilla and upper arm, the damage of terminal branches [7-9] of plexus (median nerve, musculocutaneous and ulnar nerve) is common, due to replacement of the nerve with anastomosis and vice versa, or impossibility to differentiate some of the terminal branches of plexus or their variations (such as the absence of bifurcation of trunci and fasciculi, and variations non separation) [10-12]. Injuries may vary from insignificant superficial nervous truncus damage, to partial or complete interruption of the nervous truncus [13-15]. The discontinuity or injuries of the truncus and its nerves may cause the paralysis of muscles and loss of sensibility within the area of their innervation. Not every time does the discontinuity of the nerve lead to paralysis of corresponding muscle group, due to voluminous anastomosis, where nerve impulses through anastomosis enter to the dissected nervous truncus [16-20].

\section{The Objectives}

Concerning frequent injuries of terminal branches of the lateral and medial fasciculi, as well as substantial pathology of brachial plexus, the aim of our research was to eventually expand the previous scientific knowledge in this field.

Therefore, the aim of our research was to study:

- Surgical-anatomical relations between terminal branches of medial and lateral fasciculi,

- Syntrophic and skeletal relations of these elements, which are of great importance in surgery of the neck, shoulder, upper arm and thorax,

- Substantial morphology of terminal branches of both fasciculi, particularly concerning the site and way of their origin, and their anastomosis.

Complying with objectives, the following aims of the study are:

1. To determine morphological variations in the way of origin and the site of the onset of large terminal branches of the medial and lateral fasciculus, which are most commonly damaged: radix medialis nervi mediani, n. ulnaris, radix lateralis nervi mediani, n. medianus and n. musculocutaneus.

2. To determine the morphology of the aforementioned nerves in the region of the axilla and arm: the appearance, shape, length, thickness, etc.

3. To determine the existence of anastomosis of these nerves, both between themselves and with other adjacent and surrounding nerves.

\section{Material and Methods}

The study of the terminal branches of lateral fasciculus in our preparation material is based on the dissection of the axilla and the anterior part of the upper arm, on 50 cadavers, adults of both genders, at the Anatomical Institute and the Institute of Forensic Medicine of the School of Medicine in Belgrade.

We performed the dissection on 24 female cadavers and 26 male cadavers, which amounted to 48 and 52 dissected cases, respectively. Moreover, in 48 dissected cases in females, 24 were performed on the left and 24 on the right hand side, while in 52 male cadavers, 26 were done on the left and 26 on the right hand side in order to facilitate and have better comparison. Subsequently, the total number of cases in our study equals to 100 .

During the dissection we recorded all possible differences, in relation to the right and left hand side as well as in relation to the eventual differences in gender, in order to determine the prevalence of some morphological variations on the left or right side, i.e. in women and men.

The dissection was performed by making medial incision along sulcus bicipitalis medialis, from the clavicular bone to the middle of the elbow. At the end of this incision, we made cross-cuts to increase the area of examined field. After the separation of the skin and the subcutaneous elements, we detached the tendons of $\mathrm{m}$. pectoralis major and $\mathrm{m}$. pectoralis minor, which were then removed. Next, we eliminated parts of deltoid muscle (pars acromialis et pars clavicularis musculi deltoidei). Subsequently, we obtained three prominent topographic points: acromion, processus coracoideus and margo anterior claviculae, from which we later performed different measurements. They included: the distance of the point or position of the bifurcation of the lateral fasciculus, the distance of the site or point of junction with n.medianus, and the distance of the bifurcation point of the lateral fasciculus from the bone topographic elements mentioned above.

The point of bifurcation of the lateral fasciculus is also the site of the onset of n.musculocutaneus, and the site of the occurrence of the lateral root of the median nerve (radix lateralis nervi mediani). Junction point for the both roots of the median nerve also represents a point of origin or the development of n.medianus itself. Such anatomical topography indicates the importance of knowing the variability of these distances. It should be noted that during all dissections and measurements, the upper extremity was maintained in a position of medium abduction and supination, which is a normal middle position of the arm.

The following elements were taken into account: the length, the thickness and the shape of the nervous truncus. Furthermore, we noted the existence of variations in the origin and the path of mentioned nerves, and the number and variations of their lateral branches. The great attention was given to the anastomosis of the examined nerves that were sometimes quite frequent and well expressed, and may cause confusion when it comes to differentiation of individual nervous truncus. The study is specifically 
focused to the anastomosis of the median nerve, which has a central position and the greatest thickness in relation to the abovementioned nerves. The intention was to present its anastomosis with musculoskeletal nerve (n. musculocutaneus) and elbow nerve (n.ulnaris). We carried out the classification of all anastomosis and classified them into several types, for easier orientation and identification of morphological variations of these anastomoses.

\section{The Results}

\section{Results of the research of terminal branches of lateral fasciculus}

The way in which the lateral fasciculus was formed in our preparation materials was always the same. These branches were usually formed by bifurcation or diverging of lateral fasciculus on radix lateralis nervi mediani and nervus musculocutaneus. Exceptionally, in the fusion of the lateral fasciculus with the inner root of the medianus there is no bifurcation and the formed nerve truncus is the result of the existence of a pre or post-fixation type of brachial plexus.

The site of the formation of the terminal branches of the lateral fasciculus (LF) corresponds to the point of bifurcation of LF, which is variable and of whose height depends the length of musculocutaneous nerve (NMC) and the lateral root of the n. medianus (RLNM) (Table 1).

Analyzing our dissected material, we found that high bifurcation of LF exists in $18 \%$ of cases, and they are positioned at the height of the front edge of the clavicular bone. Medium high LF bifurcation is projected at the height of the top of the scapular bone (processus coracoideus scapulae) and is found in $61 \%$ of all cases. Low bifurcation, usually found at the height of the lower edge of the musculus pectoralis minor, is found in $8 \%$ of cases. The absence of bifurcation was registered in $13 \%$ of cases. Measuring the shortest distance from the front edge of the clavicula to the point of bifurcation of LF, we obtained the results that vary in wide range of 0.5 to $9.7 \mathrm{~cm}$, average $4.2 \mathrm{~cm}$.

\section{Nervus musculocutaneus (NMC)}

It is well known that nervus musculocutaneus (NMC) is a lateral branch of the lateral fasciculus (LF), which passing the point of bifurcation proceeds downwards, diagonally and laterally. Upon entering the upper arm, it usually perforates m.coracobrachialis diagonally, and then descends between $\mathrm{m}$. biceps brachi and m.brachialis. Then, it appears in the bicipital groove, along the lateral edge of $\mathrm{m}$. biceps, and descends downwards, ending at $1-3 \mathrm{~cm}$ above epicondylus lateralis humeri, where it provides its final skin branch: nervus cutaneous antebrachii lateralis.

Reviewing our dissected material, we found nervus musculocutaneus (NMC) piercing $\mathrm{m}$. coracobrachialis (MCB) in $86 \%$ of all cases. That way, the MCB justifies the name of the pierced muscle (m.perforatus), given by Casserius back in the 16th century. Within this percentage, we also included cases where NMC pierces another muscle of the anterior part of the arm, and not MCB.

In $14 \%$ of our preparation material, NMC does not break through the MCB, but following the medial edge of the MCB and while passing that way, provides the branches for the innervation of $\mathrm{m}$. biceps brachii, $\mathrm{m}$. coracobrachialis and m.brachialis. In the lower third of the upper arm, in these cases, the NMC turns laterally, between $\mathrm{m}$. biceps and $\mathrm{m}$. brachialis, appearing in sulcus bicipitalis lateralis, giving its final branch just above the lateral epicondylus of the humerus. As seen, there are significant deviations from the classic description of the route of delivery and the NMV path, which must be kept in mind in surgical interventions in the area of the axilla and upper arm. Variations in MCB perforation, as well as variations of the NMV path, according to our observations, are almost equally represented in both male and female, as well as on the right and left extremities of the examinees. This is somewhat confirmed by the literary data, obtained and published in professional literature in the last 10 years.

\section{a) Types of perforation of the muscle coracobrachialis (MCB) by musculocutaneous nerve $(N M C)$}

Analyzing the method of MCB perforation by NMV on our dissected material, we found that there are 2 basic forms of perforation: superficial and deep.

Table 1 Explored cadaveric material

\begin{tabular}{|c|c|c|c|c|c|c|c|c|c|c|}
\hline \multicolumn{5}{|l|}{ Examined Material } & \multicolumn{4}{|c|}{ Position of bifurcation of FL } & \multicolumn{2}{|c|}{$\begin{array}{c}\text { Perforation of MCB from } \\
\text { NMC }\end{array}$} \\
\hline \multirow[t]{2}{*}{ Gender } & Number & Material & Left & Right & $\begin{array}{c}\text { High } 1 \\
\text { bifurcation }\end{array}$ & $\begin{array}{l}\text { Medium high } \\
\text { bifurcation }\end{array}$ & $\begin{array}{c}\text { Low } \\
\text { bifurcation }\end{array}$ & $\begin{array}{c}\text { Non } \\
\text { Existant }\end{array}$ & Present & Not present \\
\hline & 50 & 100 & 50 & 50 & $18 \%$ & $61 \%$ & $8 \%$ & $13 \%$ & $86 \%$ & $14 \%$ \\
\hline Female Cadavers & 24 & 48 & 24 & 24 & & & & & & \\
\hline Male Cadavers & 26 & 52 & 26 & 26 & & & & & & \\
\hline \multicolumn{5}{|c|}{ Points of occurrence } & $\begin{array}{l}\text { Clavicular } \\
\text { bone }\end{array}$ & $\begin{array}{c}\text { Processus } \\
\text { coracoideus }\end{array}$ & $\begin{array}{l}\text { m. pectoralis } \\
\text { minor }\end{array}$ & & & \\
\hline \multirow{2}{*}{\multicolumn{5}{|c|}{$\begin{array}{l}\text { Deep perforation } \\
\text { Superficial perforation } \\
\end{array}$}} & & & & & $80 \%$ & \\
\hline & & & & & & & & & $6 \%$ & \\
\hline Total & 50 & 100 & 50 & 50 & \multicolumn{4}{|c|}{$100 \%$} & \multicolumn{2}{|c|}{$100 \%$} \\
\hline
\end{tabular}


Table 2 Analysis of the results of the research of the terminal branches of the lateral fasciculus

\begin{tabular}{|c|c|c|c|c|c|c|c|c|c|c|}
\hline \multicolumn{4}{|c|}{ Angle of perforation measurements } & \multicolumn{5}{|c|}{$\begin{array}{l}\text { Types of perforations } \\
\text { of MCB by NMC }\end{array}$} & \multicolumn{2}{|c|}{$\begin{array}{c}\text { Anastomosis of NM } \\
\text { with NMC }\end{array}$} \\
\hline & $\begin{array}{l}\text { Minimal } \\
\text { value }\end{array}$ & $\begin{array}{l}\text { Mean } \\
\text { value }\end{array}$ & $\begin{array}{l}\text { Maximum } \\
\text { value }\end{array}$ & $\begin{array}{c}\text { High } \\
\text { perforation }\end{array}$ & $\begin{array}{l}\text { Medium } \\
\text { high } \\
\text { perforation }\end{array}$ & $\begin{array}{c}\text { Low } \\
\text { perforation }\end{array}$ & $\begin{array}{l}\text { Perforation } \\
\text { of other } \\
\text { muscles } \\
\text { instead of } \\
\text { MCB }\end{array}$ & $\begin{array}{l}\text { Double } \\
\text { perforati } \\
\text { on }\end{array}$ & $\begin{array}{c}\text { When } \\
\text { NMC } \\
\text { derives } \\
\text { from FL }\end{array}$ & $\begin{array}{c}\text { When } \\
\text { NMC } \\
\text { derives } \\
\text { from FNS }\end{array}$ \\
\hline $\begin{array}{l}\text { High } \\
\text { perforation }\end{array}$ & 10 & 16 & 18 & & & & & & & \\
\hline $\begin{array}{l}\text { Medium high } \\
\text { perforation }\end{array}$ & 19 & 21 & 26 & & & & & & & \\
\hline $\begin{array}{l}\text { Low } \\
\text { perforation }\end{array}$ & 33 & 39 & 45 & $51 \%$ & $17 \%$ & $7 \%$ & $3 \%$ & $2 \%$ & $31 \%$ & $6 \%$ \\
\hline $\begin{array}{l}\text { Superficial } \\
\text { perforation }\end{array}$ & 6 & 9 & 11 & & & & & & & \\
\hline \multirow{2}{*}{\multicolumn{4}{|c|}{$\begin{array}{l}\text { One anastamosis } \\
\text { Two anastamosis }\end{array}$}} & & & & & & $27 \%$ & \\
\hline & & & & & & & & & $4 \%$ & \\
\hline \multicolumn{4}{|l|}{$\overline{\text { Variation A }}$} & & & & & & & $3 \%$ \\
\hline \multicolumn{4}{|l|}{ Variation B } & & & & & & & $2 \%$ \\
\hline \multicolumn{4}{|l|}{ Variation $\mathrm{C}$} & & & & & & & $1 \%$ \\
\hline Total & & & & & $100 \%$ & & & & & \\
\hline
\end{tabular}

Superficial perforations of the MCB are in those cases where the NMC, when perforating the MCB, superficially involves only a few muscle fibers, which are transferred as a bridge over the nerve. This can occur in any segment of the MCB, in $\mathrm{m}$. brachialis or m. biceps brachi instead of MCB, or it can be observed as double perforation, when two muscles are penetrated repeatedly (both superficially, or one superficially and one deeply) (Table 2).

Deep perforation of MCB occurs when NMC passes through the MCB muscle body, forming both shorter and longer muscle tunnels in the MCB. In this situation, deep perforation of MCB can occur in its upper, middle or lower part, and therefore we distinguish high, medium and low perforation of the $\mathrm{m}$. coracobrachialis (MCB). Deep perforation can also be found if another muscle is perforated instead of MCB (m. biceps brachii or $\mathrm{m}$. brachialis), as well as in double perforation, when another muscle is perforated along with the MCB. According to our findings, perforation of MCB or some other muscle happens in $86 \%$ of cases (in $80 \%$ of these cases, we noted deep perforation, and in $6 \%$, it was superficial).

\section{b) Deep perforation forms of $M C B$}

The high perforation of MCB by NMC occurs in $51 \%$ of cases in our material. In this case, NMC after separation from the LF perforates the MCB diagonally in its upper third, making a rather long muscular tunnel in the MCB muscle body. The point of entry of the nerve into the muscle is at the back of the muscle, while the point where the nerve exits the muscle is usually on its front. We noted that in case of the high perforation of MCB, the muscle tunnel is the longest, because the nerve passes through biggest part of the muscle mass of the MCB.
During this perforation, there is an incomplete but correct division of the muscle into two parts: the upperouter part which is smaller and the lower-inner part is much larger, and the boundary between represents the NMC itself in its muscular tunnel (Figs 1-4).

Medium to high perforation of MCB was observed in our material in $17 \%$ of cases and is second in frequency. In this form of perforation, NMC perforates the MCB in the middle third of its muscular mass, making the muscular tunnel of medium length. It is often encountered in low or medium high bifurcation of the lateral fasciculus (LF). The muscular tunnel is located in the middle of the MCB, and in it the NMC divides the muscle into two almost identical parts: the upper-outer and lower-inner part. Since the MCB muscle body in this part is rounded, the point of entry and the point of NMC exit are in the front area of the muscle.

Low perforation MCB was found in $7 \%$ of cases. There may be a low LF bifurcation, although it is not mandatory because it is also seen in high bifurcation LF. Perforation occurs in the lower third of the muscular body, which is at this height of spindle-like appearance, gradually narrowing into the ultimate tendon with attachment on the medial side or edge of humerus (tuberositas coracobrachialis). The muscle tunnel formed by passing of NMC through the lower third of the MCB is about the same direction as in the previous perforations, but it is significantly shorter in comparison to the high and middle perforation, due to the fact that at this point the muscle mass is significantly reduced since the muscle exceeds its final tendon. The point of entry and the point where the nerve comes out of the muscle is located on the inner and outer sides of the lower body of the muscle, where the NMC divides the muscle into two uneven parts: the upper-outer part and the much smaller lower-inner part. 


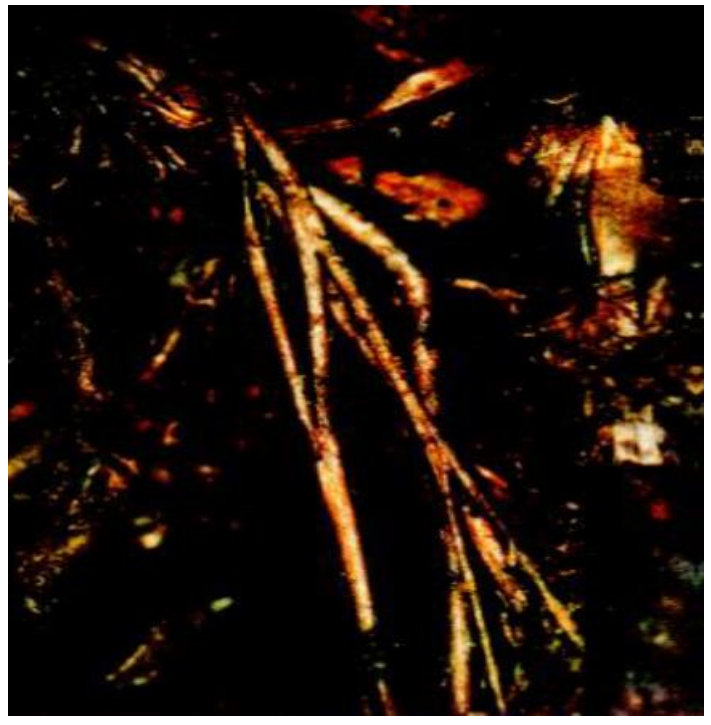

Fig. 1 Slim RLNM and RMNM, NMC is thick and separates the medial diagonal anastomosis for NM, which becomes thicker. NMC perforates the MCB and gives 2 branches before perforating the MCB, NU is behind $\mathrm{NM}$, visible at the bottom of the image.

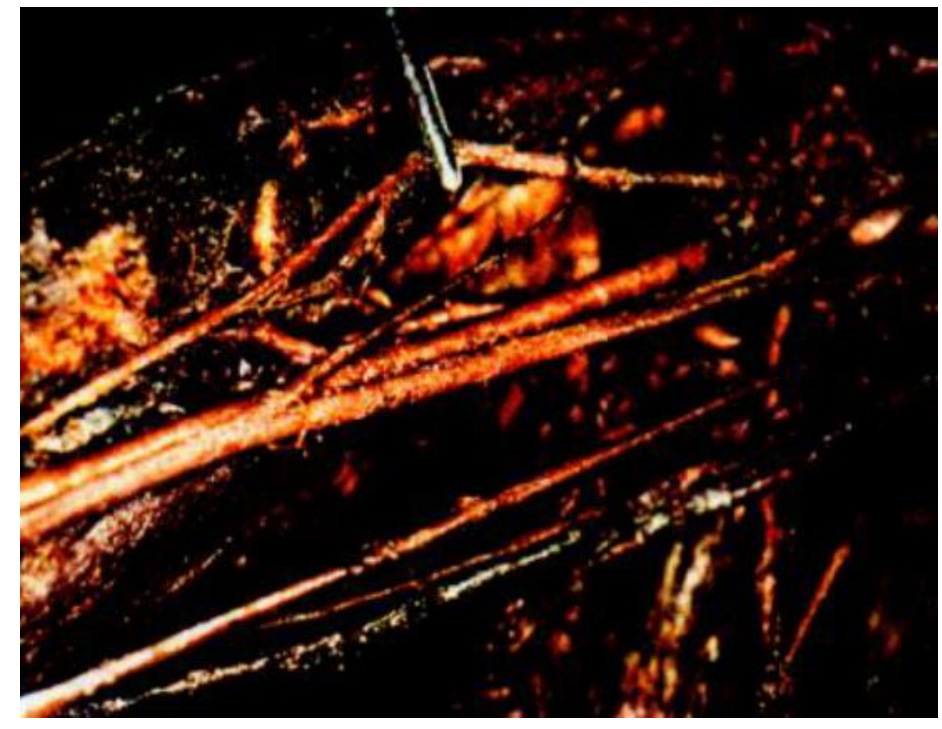

Fig. 2 FL is clearly seen, with NMC that perforates MCB, and short RLNM. We detect RMNM, which is longer than RLNM, part of FM and NU. Fine thin upper diagonal anastomosis between NMC and NM.

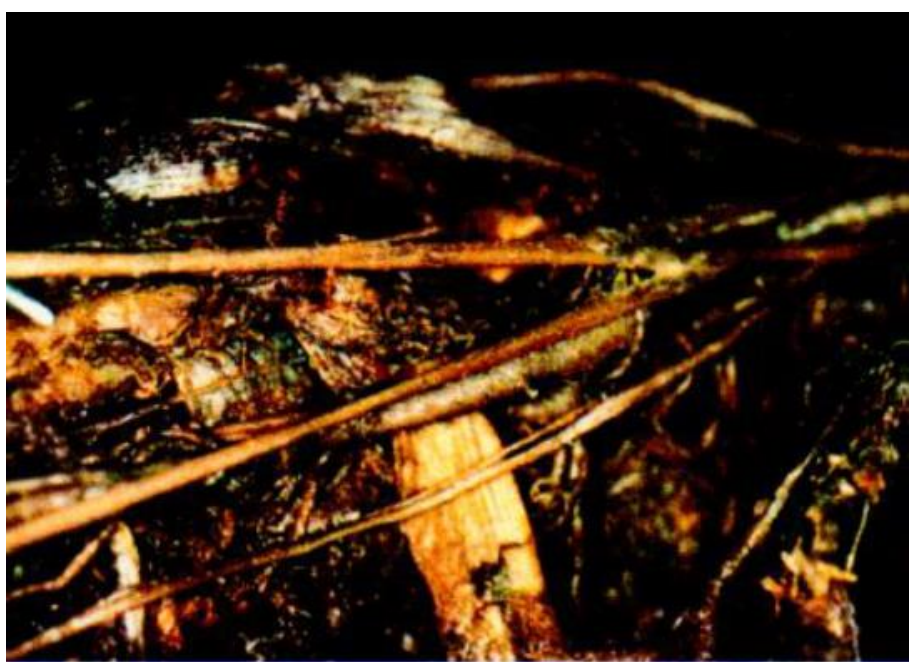

Fig. 3 FL is less visible and FM well detectable, classical appearance of NM. In the lower part, the presence of long thin anastomosis between NU and NCAM.

Perforation of another muscle instead of MCB was found in $3 \%$ of cases, of which the 2 perforations were of the short head of the biceps $(2 \%)$ and 1 case of $\mathrm{m}$. brachialis perforation (1\%). In two cases of caput breve musculi bicipitis brachii, we found the usual division of $\mathrm{LF}$, and the perforation was performed in the upper third of the short head of muscle in the first case, and in the second case in the middle third of the short biceps head. After passing through short head of $\mathrm{m}$. biceps, in both cases the NMC was superficial and subcutaneous, and after crossing the long head, it went along the sulcus bicipitalis lateralis and continued its usual path. The

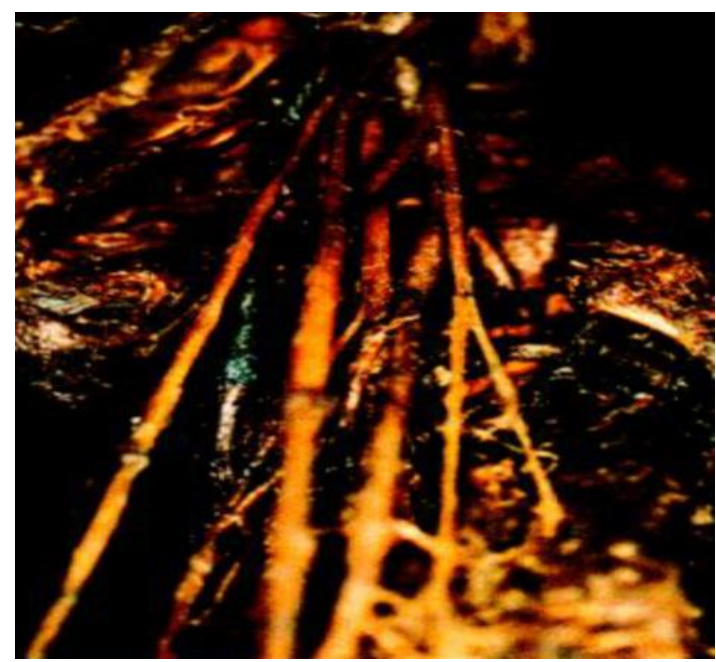

Fig. 4 High origin point of NM and well expressed anastomosis (NMC-NM) below. $\mathrm{NMC}$ does not perforate $\mathrm{MCB}$ and gives a branch for MCB and MBB.

length of the muscular tunnel in the short head in the first case was $3.7 \mathrm{~cm}$ and in the second case $2.8 \mathrm{~cm}$. In the case of perforation of $\mathrm{m}$. brachialis, NMC, after its usual occurrence, went along the inner edge of the $\mathrm{MCB}$, and in the lower third of this muscle, its direction goes diagonally and laterally, between $\mathrm{m}$. biceps and $\mathrm{m}$. brachialis, deeply involving the second muscle, creating a $3.2 \mathrm{~cm}$ long muscle tunnel. It then goes into the outer bicipital groove from where it continues its usual path, to the epicondylus lateralis, where it gives the final branch - nervus cutaneus antebrachii lateralis. 
Double perforation or perforation of two muscles with the same nerve, in our material, was documented in $2 \%$ of cases. In both cases, NMC had a usual origin, with high MCB perforation. Upon leaving the MCB, the NMC kept the deep side of the long biceps head in a length of $3.2 \mathrm{~cm}$, while in the second case, diagonally perforated both short and long head in length of $4.3 \mathrm{~cm}$. After entering the sulcus bicipitalis lateralis, both nerves continued the usual pathway for the NMC, with the separation of the small lateral and well-defined terminal branches of this nerve.

\section{c) Superficial perforation of $M C B$ by $N M C$}

This phenomenon is noticed in $6 \%$ of our material, although it is rarely mentioned in the professional literature. This relatively significant percentage observed in our preparation material is a consequence of careful preparation material, since the fibers of MCB that cover NMC are small and thin and easily ruptured by harsh and inadequate dissection technique.

Unlike other authors, we consider that the superficial perforation can be observed in the lower, as well as in the middle and upper thirds of the MCB. Moreover, we have found it 4 times in the lower third, 2 times in the middle and 1 time in the upper third of the MCB.

In this case, the muscular tunnels are very short, and we can call them muscle bridges over the NMC, and their length range goes from 0.4 to $0.9 \mathrm{~cm}$.

In the literature, it is also described the double superficial perforations (MCB with $\mathrm{MBB}$ or $\mathrm{MB}$ ) or perforation of any other muscle without MCB perforation. We have not observed such cases in our study.

\section{d) Variations in the distribution of lateral branches of NMC}

During the dissection, we observed and recorded the way of formation and morphological variations of lateral branches of the NMC.

We focused on the following lateral branches of NMC: ramus vascularis, ramus articularis, ramus osseus, nervus musculi coracobrachialis superior, nervus musculi coracobrachialis inferior, nervus musculi brachialis and nervus musculi bicipitis brachii.

Ramus vascularis, a non-permanent branch, was observed in $7 \%$ of cases. It is usually separated from the supramuscular segment of NMC, after division from the LF or before entering the MCB. It innervates the walls of the following blood vessels in the form of a network of fine thin branches, followed by: a. circumflexa humeri anterior, vv. circumflexae humeri anteriores, a. circumflexa humeri posterior, vv. circumflexae humeri posteriores.

Ramus articularis, a non-permanent branch, occurs in $9 \%$ of cases. It usually separates from NMB in $6 \%$ of cases, or from extramuscular part of NMC in $3 \%$ of cases. One or more branches lead to the articular capsule of the elbow (articulatio cubiti).

Ramus osseus, a non-permanent branch, is found in $17 \%$ of cases. It is separated from the intramuscular segment of NMC (10\%) or from the extramuscular segment of NMC (7\%). This nerve follows a. nutritia humeri and together they enter the foramen nutritium on humerus.

Nervus musculi coracobrachialis superior is constant branch but highly variable. It occurs from the supramuscular part of the NMC (81\%), from the external root of n. medianus (RLNM) $(3 \%)$, from the FL (11\%) or from FNS (FL with RMNM) (5\% of cases).

Nervus musculi coracobrachialis inferior is a constant branch that was observed in $90 \%$ of the cases as the branch of the lower part of the truncus of NMC, and in $10 \%$ of cases as the branch of the fused nerve truncus (LF plus RMNM).

Nervus musculi brachialis is a constant, voluminous branch, the second thickest branch, which separates usually in the intramuscular segment of NMC, below the biceps branch $(80 \%)$ or in the upper part of the tunnel $(20 \%)$.

Nervus musculi bicipitis brachii is a constant, thickest branch of the NMC. It separates in the center of the tunnel from NMC, by a unique truncus, in $75 \%$ of cases. This truncus is later divided into nervus capitis brevis musculi bicipitis brachii and nervus capitis longi musculi bicipitis brachii. In $5 \%$ of cases, both nerves start separately from the NMC, at the beginning of the tunnel, and in $10 \%$ of cases also separately, at the end of the muscle tunnel.

\section{Radix lateralis nervi mediani (RLNM)}

The lateral root of n.medianus, after separation from the FL, descends diagonally downward and inward, to connect at the front side of a. axillaris with the medial root of $n$. medianus, whereby forming the central nerve of the arm - n. medianus.

The shape of the nerve at the cross-section of the nervous truncus is regular and round in the upper part, while in the lower part it remains flat, due to the pressure of the nerve on the wall of a. axillaris. Concerning its thickness, it is sometimes very thin, and in these cases usually there is an anastomosis just below it, which enhances the lateral root of $n$. medianus.

Some anatomists tend to refer to RLNM and anastomosis beneath it as a double or separated lateral root of n. medianus. However, it was definitely established that this is a high upper-internal anastomosis between NMC and $\mathrm{NM}$ in $5 \%$ of cases.

In terms of the length of this root, we noticed that there is a great variability. According to our measurements, the minimum length of the RLNM is $9 \mathrm{~mm}$, the middle root length is $3.4 \mathrm{~cm}$ and the maximum value is $13.5 \mathrm{~cm}$. In the last case, RMNM is even longer, due to a very low start position of $\mathrm{n}$. medianus.

In $13 \%$ of cases, there is no RLNM in our material, as there was no division of FL, but the entire FL was merged with RMNM and formed a fused thick nervous truncus. It essentially contains NMC, RLNM and RMNM.

Regarding the distribution of lateral branches, RLNM is very poor. Thus, as already mentioned, it has been observed that in $3 \%$ of the cases, RLNM provides 
the upper branch nerve to m.coracobrachialis (nervus musculi coracobrachialis superior).

In one preparation material only, we observed an extremely rare case in which RLNM provides the root or branch for n.ulnaris (1\% of cases). The root is quite voluminous, and it significantly enhances the diameter of ulnar nerve. A similar case was not found in the professional literature published over the last 10 years, although we are familiar with the great morphological variability of the terminal branches of plexus brachialis, including its various anastomoses.

In our materials we also measured the angle of bifurcation of the LF, the angle of junction of roots of n.medianus, as well as the angle of bifurcation of the $\mathrm{MF}$, since these angles are in mutual correlation.

\section{Discussion}

Analyzing the previously published research results, our findings can be compared with the results of other authors.

Terminal branches of LF in $87 \%$ of cases derive from bifurcation of LF to NMC and RLNM, while in $13 \%$ of cases they occur from the fused nervous truncus. High LF bifurcation is noted in $18 \%$ of cases, medium high in $61 \%$ and low bifurcation in $8 \%$ of cases. The results of some researches [19-20] show that in $89 \%$ terminal branches of LF appear from bifurcation to NMC and RLNM, while in $11 \%$ of cases they appear from the fused nervous truncus. The distance from the anterior edge of the clavicular bone to the point of bifurcation of LF, amounts to an average $4.2 \mathrm{~cm}$, and the extreme values are $0,5 \mathrm{~cm}$ and $0.7 \mathrm{~cm}$, which correlates with intraoperative findings [21].

Nervus musculocutaneus (NMC) in $86 \%$ of cases perforates $\mathrm{MCB}$, and therefore, this muscle deserves the name of musculus perforates, given by Casserius back in the 16th century. In $14 \%$ of cases, NMC does not perforate MCB, but follows the internal edge of the MCB, after which it continues its usual path. In $13 \%$ of cases, in reports, NMC does not perforate the MCB, but follows the anterior edge of the MCB [12,20,21,22]. Out of $86 \%$ of the cases when NMC perforates MCB, in $51 \%$ of cases there is high MCB perforation by NMC and in $17 \%$ of cases - a medium high perforation, and in $7 \%$ of cases - a low perforation. In $3 \%$ of cases, there is perforation of another muscle instead of MCB (MBB, $\mathrm{MB}$ ), while in $2 \%$ of cases, there is perforation of 2 muscles with the same nerve (double perforation). The described cases of perforation (89\%) belong to the deep perforation type, while in $6 \%$ of cases, a type of superficial perforation is noticed (when the muscle was affected superficially), which is $86 \%$ in total. This research is in correlation to other authors' research [12,18,23-26].

In the case of MCB perforations, the NMC with the humerus axis forms the angle of perforation. The average value of this angle at high bifurcations is $16^{\circ}$ ( $\mathrm{min} .10^{\circ}$, max. $\left.18^{\circ}\right)$, at a medium high $21^{\circ}\left(\min .19^{\circ}\right.$, max. $\left.26^{\circ}\right)$ and at low bifurcations $39^{\circ}\left(\min .33^{\circ}\right.$, max. $\left.45^{\circ}\right)$. In superficial perforations, the angle becomes sharp again and amounts to an average $9^{0}\left(\min .6^{0}, \max .11^{0}\right)$. In available literature, we have not found the related data to compare with our results.

Due to the perforation of MCB by NMC, a muscle tunnel is formed, in which the intramuscular segment of the NMC is located and wrapped with connective tissue. The average length of the tunnel is $3.4 \mathrm{~cm}$, minimum $4 \mathrm{~mm}$ for superficial perforations, and maximum $11 \mathrm{~cm}$. In $83 \%$ of cases, the tunnel is simple and in the form of tubes, while in $3 \%$ of cases, it also contains one or two accessory anastomosis muscle tunnels.

On the histological material of the muscular tunnel, the NMC is seen transversally cut, centrally positioned, with clear fascicular structures and sheaths, with the presence of a large number of epi- and peri-neural blood vessels. The layer of loose connective tissue comes next, protects the nerve from injury and allows easier sliding movement through the tunnel, in different movements in the shoulder and elbow joint. Behind it is a layer of transverse muscle fibers, which form the tunnel walls.

In terms of the distribution of lateral branches of NMC, we noted the following: ramus vascularis $(7 \%)$, ramus osseus (17\%) and rami articularis (9\% of cases), with different variation of genesis. We also distinguished four constant branches: $\mathrm{n}$. MCB superior, n. MCB inferior, n. musculi brachialis and n. musculi bicipitis brachii, with great variability of their origin. The same conclusions were made in other researches [6,9,11,13,27-31].

Radix lateralis nervi mediani (RLNM) does not show many morphological variations. The average root length is $3.4 \mathrm{~cm}$, maximum $13.5 \mathrm{~cm}$ and minimum $9 \mathrm{~mm}$.

In $13 \%$ of cases, RLNM does not exist because FL has merged with RMNM and formed a fused nerve truncus, while in 5\% of cases there is a double RLNM, which is in fact a high upper anastomosis between NMC and NM. In $3 \%$ of the RLNM dissected material, there is a upper branch for MCB (n. MCB superior), and in an extremely rare case $(1 \%)$ it gives the anastomotic branch for the elbow nerve (n.ulnaris). In some researches, the results have showed that in $14 \%$ of cases RLNM does not exist, due to the fusion and formed fused truncus [13,16-18,32].

\section{Conclusion}

The origin of terminal branches of lateral fasciculus in our prepared material was always the same. These branches were usually formed by bifurcation or diverging of lateral fasciculus to radix lateralis nervi mediani and n. musculocutaneus. Exceptionally, fusing the lateral fasciculus with medial root of $n$. medianus, there is no bifurcation, and the formed nervous truncus is a result of existence of the pre- or postfixational type of brachial plexus.

During the surgical interventions in axillar and upper arm area, or postoperative, the transitory paralysis of some terminal branches of brachial plexus are described, including transitory paralysis of $n$. medianus, $n$. 
ulnaris and $\mathrm{n}$. musculocutaneus. They occur due to the damage of wall and the rupture of arteries of these nerves (arteria nervi mediani, vasa nervi musculocutanei, vasa nervi ulnaris). Therefore, postoperative ische-

\section{References}

1. Standring S. Gray's anatomy: the anatomical basis of clinical practice. 39th ed. London: Elsevier Churchill Livingstone; 2005.

2. Nayak BS, Soumya KV. Abnormal formation and communication of external jugular vein. Int J Anat Var 2008; 1:15-6.

3. Bakirci S, Kafa IM, Uysal M, Sendemir E. Langer's axillary arch (axillopectoral muscle): a variation of latissimus dorsi muscle. Int $\mathbf{J}$ Anat Var 2010; 3:91-2.

4. Pai MM, Rajanigandha, Prabhu LV, Shetty P, Narayana K. Axillary arch (of Langer): incidence, innervation, importance. Online J Health Allied Sci 2006; 5:4

5. Bertha A, Kulkarni NV, Maria A, Jestin O, Joseph K. Entrapment of deep axillary arch by two roots of radial nerve: An anatomical variation. J Anat Soc India 2009; 58:40-3.

6. Iamsaard S, Uabundit N, Khamanarong K, Sripanidkulchai K, Chaiciwamongkol K, Namking M, Ratanasuwan S, Boonruangsri P, Hipkaeo W. Duplicated axillary arch muscles arising from the latissimus dorsi. Anat Cell Biol 2012; 45:288-90.

7. Pillay M, Jacob SM. Bilateral presence of axillary arch muscle passing through the posterior cord of the brachial plexus. Int $\mathbf{J}$ Morphol 2009;27:1047-50.

8. Guy MS, Sandhu SK, Gowdy JM, Cartier CC, Adams JH. MRI of the axillary arch muscle: prevalence, anatomic relations, and potential consequences. AJR Am J Roentgenol 2011;196:W52-7.

9. Bhat KM, Gowda S, Potu BK. Nerve loop around the axillary vessels by the roots of the median nerve a rare variation in a south Indian male cadaver: a case report. Cases J 2009; 2:179.

10. Siqueira MG, Martins RS. The controversial arcade of Struthers. Surg Neurol 2005; 64 Suppl 1:S1:17-20.

11. Brunelli G, Monini L. Neurotization of avulsed roots of brachial plexus by means of anterior nerves of cervical plexus. Clin Plast Surg 1984; 11(1):149-52.

12. Ihara K, Doi K, Sakai K, Kawai S, Kuwata N. Sensory reconstruction for total brachial plexus palsy of root-avulsed type. J Jpn Soc Surg Hand 1992; 9:472-5

13. Kotani T, Toyoshima Y, Matsuda H Suzuki T, Ishizaki Y. The postoperative results of nerve transfer for the brachial plexus injuries with root avulsion. Seikeigeka 1971; 22:963-66.

14. Nagano A, Tsuyama N, Ochiai N, Hara T, Takahashi M. Direct nerve crossing with the intercostal nerve to treat avulsion injuries of the brachial plexus. J Hand Surg Am 1989; 14(6):980-5. https://doi.org/10.1016/S0363-5023(89)80047-4

15. Nakatuchi $Y$, Saitou S, Hosaka M, Tada H, Kamidaira M. Reconstruction of sensory function for brachial palsy. J Jpn Soc Surg Hand 1988; 5:156-60.

16. Williams PL, Bannister LH, Berry MM. Thoracic ventral rami. In: Williams PL, Bannister LH, Berry MM, editors. Gray's anatomy. 38th ed. London: Churchill Livingstone; 1999. p. 1275-76.

17. Morrow M. Segmental mastectomy and axillary dissection. In: Baker RJ, Fischer JE, editors. Mastery of surgery. 4th ed. Philadelphia: Lippincott Williams and Wilkins; 2001. p. 588-96. mia of nervous truncus automatically continues after paralysis. This paralysis is transitory, so as soon as the irrigation of the nerve is normalized, the paralysis vanishes.

18. Kubala $\mathrm{O}$, Prokop J, Jelínek $\mathrm{P}$, Ostruszka $\mathrm{P}$, Tošenovský J, Ihnát $\mathrm{P}$ et al. [Anatomic-surgical study of intercostobrachial nerve (ICBN) course in axilla during I and II level of axilla clearance in breast cancer and malignant melanoma]. Rozhl Chir 2013; 92(6):320-9. Czech.

19. Loukas M, Hullett J, Louis RG Jr, Holdman S, Holdman D. The gross anatomy of the extrathoracic course of the intercostobrachial nerve. Clin Anat 2006; 19(2):106-11. https://doi.org/10.1002/ ca.20226

20. Khan A, Chakravorty A, Gui GP. In vivo study of the surgical anatomy of the axilla. Br J Surg 2012; 99(6):871-7. https://doi.org/ 10.1002/bjs.8737

21. Samardžić M, Rasulić L, Grujičić D, Miličić B. Results of nerve transfer to the musculocutaneous and axillary nerves. Neurosurgery, 2000; 46:93-103.

22. Rasulić L, Samardžić M. Povrede brahijalnog pleksusa. In: Samardžić M. Rasulić L, eds). Hirurgija perifernih nerava savremeni stavovi. Beograd: I.P. Obeležja; 2011. p. 32-42.

23. Rasulic L, Samardzic M, Grujicic D, Bascarevic V. Nerve transfer in brachial plexus injuries: comparative analysis of surgical procedures. Acta Chir Iugosl 2003; 50(1):33-46.

24. Samardžić M, Rasulić L, Baščarević V. Savremeni protokol hirurškog lečenja povreda perifernih nerava, International Journal Total Quolity Management \& Excellence 2010; 38(2): 169-73.

25. Vujović R, Cvrkota I, Samardžić M, Rasulić L, Baščarević V, Savić A., Lakićević N. Hirurško lečenje povreda perifernih nerava. Zdravstvena Zaštita 2012; 41(3):20-7.

26. Samardžić M, Rasulić L. Povrede i kompresije perifernih nerava u sportu, u Milinković Z. (ed). Sportska medicina u pitanjima i odgovorima. Beograd: Narodna knjiga/Alfa; 2010. p. 239-54.

27. Samardžić M., Grujičić D., Rasulić L., Miličić B.: Restoration of upper arm function in traction injuries to the brachial plexus, Acta Neurochirurgica 2002; 144:327-35.

28. Samardžić M, Grujičić D, Rasulić L, Bacetić D. Transfer of the medial pectoral nerve: myth or reality? Neurosurgery 2002150 : 1277-82.

29. Samardžić M, Rasulić L, Lakićević N, Baščarević Cvrkota I, Savić A:Collateral branches of the brachial plexus as donors in nerve transfers-Bočne grane brahijalnog pleksusa - donori u transferima nerava, Vojnosanit Pregled 2012; 69(7):594-603

30. Samardzic M, Grujicic D, Rasulic L, Bacetic D, Milicic B.: Nerve transfer in traction injuries of the brachial plexus, Vojnosanit Pregl 2003; 60(5):539-46.

31. Bojovic V, Berisavac I, Rasulic L. Significance of sensory evoked potentials in determination of the level of brachial plexus injuries. Acta Chir Iugos. 2003; 50(1):15-22.

32. Hwang K, Huan F, Hwang SW, Kim SH, Han SH. The course of the intercostobrachial nerve in the axillary region and as it is related to transaxillary breast augmentation. Ann Plast Surg 2014; 72(3):337-9. 